\title{
A DISTRIBUTED SIMULATION MODEL FOR INVENTORY MANAGEMENT IN A SUPPLY CHAIN
}

\author{
Giuseppe Confessore ${ }^{1}$, Stefano Giordani ${ }^{2}$, Giuseppe Stecca ${ }^{1,2}$ \\ ${ }^{1}$ Istituto di Tecnologie Industriali e Automazione - Sezione di Roma \\ Consiglio Nazionale delle Ricerche \\ Area della Ricerca Roma Tor Vergata, Via Fosso del Cavaliere, 100 \\ -00133 Roma-ITALY.g.confessore@itia.cnr.it, g.stecca@itia.cnr.it
}

${ }^{2}$ Dipartimento di Informatica, Sistemi e Produzione Università di Roma "Tor Vergata" Via del Politecnico 1-00133 Roma-ITALY.

\begin{abstract}
One of the challenging issues faced by each enterprise of a supply chain is to determine the right production and/or stock levels in order to minimize costs while ensuring a given customer service. In a supply chain, each enterprise pursues its own goal and takes its own decisions in an independent way. However, the decisions are usually influenced by the actions or decisions of the others. One of the main factors influencing the decision process is the customer demand originated at the downstream layer of the supply chain and traveling up the supply chain in terms of orders placed on to upstream layers and becoming more and more altered. In order to achieve high efficiency in the whole system, an effective coordination between enterprises is needed. In this paper, an analysis of how supply chain actors interact with each other and how the communication and coordination improve the efficiency of the supply chain is presented; we propose a distributed simulation model for analyzing the effect of inventory policies and information sharing on changing customer demands. The proposed model is tested on an Italian extended enterprise in which the actors cooperate to produce compressors for refrigerators.
\end{abstract}

\section{INTRODUCTION}

In a fast change environment, enterprises must respond quickly and correctly to the needs of the marketplace with the use of the means provided by new technologies. It is a survival matter to consider new solutions for factory organization [2]. In order to investigate how to tackle with these new solutions, new concepts have been introduced, like virtual organization, virtual enterprise [8], and extended factory. The extended factory is a new configuration of production systems that implies strong cooperation between different actors; it is characterized from a wealth of interactions, confidence on the mutual skills, and cooperative relationships on the development of the product. 
The purpose of this work is to examine interactions between actors in a supply chain which have to decide the right production and/or stock levels. Our study focuses on the distortion phenomenon for order information when it travels up the supply chain and its effects on inventory management policies.

In this paper, we propose a cooperation strategy model to face information distortion problem, and a distributed simulation model to study interaction and cooperation issues between actors of the supply chain.

The proposed model is tested on an Italian extended factory in which the actors cooperate to produce compressors for refrigerators; the studied enterprise is a distributed production system having three production plants and inventories managed according to particular policies.

The paper is organized as follows. In Section 2, we describe the supply chain actors, explain issues on information distortion and bullwhip effect (BE), and describe the inventory management policy adopted in the extended enterprise. In section 3, we describe the coordination rule proposed and introduce the simulation model. In Sections 4, and 5, we discuss results issued by the simulation model and make some conclusions.

\section{DISTRIBUTED PRODUCTION PROCESSES AND INFORMATION DISTORTION}

We consider a distributed production system constituted by a set of plants involved in production of compressors for refrigerators (see Figure 1). In particular, Plant 3 is dedicated to the manufacturing of material and primary components like copper and cast iron; Plant 2 produces electric motors for compressors; and Plant 1 assembles the compressors for refrigerators.

The production of compressors is highly specialized, and requires a capitalintensive production. However, for the final customer (refrigerator assembler and distribution center), the compressor is a commodity extremely standardized. The whole supply chain is completed by external suppliers and customers. In the following, we refer to a customer demand as the demand of compressors originated from the refrigerator distribution center.

Referring to the case study shown in Figure 1, we analyze the flow of the copper, represented in the figure by bold arrows. The critical path for the supply chain is given by the copper flow, and, as reported by plant managers, this can be justified by the following considerations: the copper and cast iron productions in Plant 3 are separated, and there are different inventory management policies for the two products. The cast iron does not cause bottleneck problems at Plant 1 where it is used in conjunction with the copper.

External customers are not considered because their demand is low compared to the internal demand. The external suppliers of Plants 2 and 1 can be neglected since these actors provide non-critical components for the compressor production. 


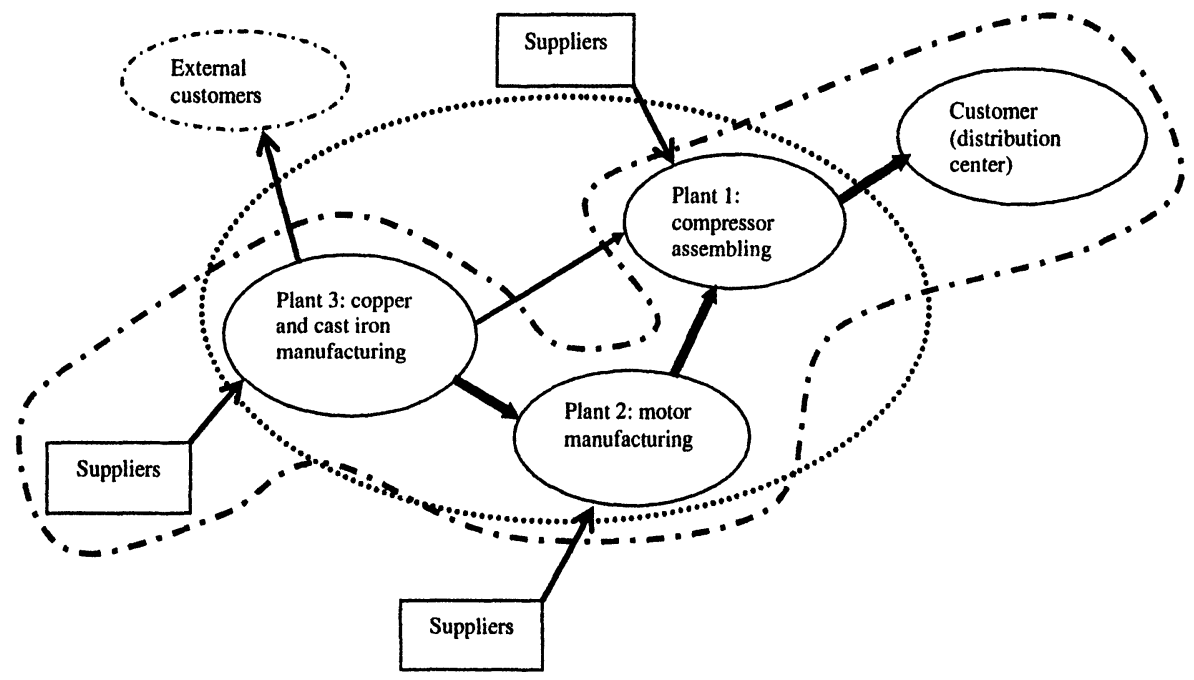

Figure 1. Supply chain of the extended factory.

\subsection{Information sharing and bullwhip effect}

Empirically, it has been noted that there is an amplification of order variability when we go up along the supply chain; this phenomenon is commonly known as bullwhip effect $[4,5,9]$. As explained in $[4,6]$, no optimal inventory management policies and information lack can highly contribute to information distortion increase.

Lots of studies (see for example $[4,5,6]$ ) have been made to quantify the bullwhip effect relatively to the factors contributing the increasing of order variability in the supply chain: demand forecasting, lead time, batch ordering, price fluctuation, and inflated orders.

The measure of bullwhip effect can be defined as the ratio $\operatorname{Var}(Q) / \operatorname{Var}(D)$ between order variance $\operatorname{Var}(Q)$ and customer demand variance $\operatorname{Var}(D)[4,5,9]$. For a supply chain with more than one stage, like the one we consider, the amplification of demand variability at stage $k$ is defined as $\operatorname{Var}\left(Q^{k}\right) / \operatorname{Var}(D)$, where $Q^{k}$ represents order quantity placed by actor $k$ to actor $k+1$. In [3], it is shown that standard inventory policies like $(s, S)$, add variability to demand values, with the variance of orders exceeding the variance of sales.

One of the possible actions that can be undertaken for reducing the bullwhip effect is to implement an organizational model based on centralized information. This consists in providing every level of the supply chain with complete information on the actual customer demand.

\subsection{Inventory management policy}

In this section, we analyze the inventory policy adopted in the extended enterprise that can be assumed to be a $(s, S)$-like policy ( $s$ is the reorder point and $S$ is the order-up to level). Differently from works introduced before, in this work we deal 
with some variations of the standard inventory management policy that reflect real applications.

In our case study, each actor of the considered supply chain (i.e., Plants 1, 2, and 3 ) has two different inventories for raw materials (stocked in an input inventory) and finished goods (stocked in an output inventory), respectively. Inventories are continuously monitored: the input inventory operates according to the $(s, S)$ policy, while the output inventory faces a daily order to the production facility (i.e., the daily production rate required), according to a weekly production plan computed on the basis of forecasted demand, with a maximum daily production rate for all plants assumed to be approximately equal to 20 units (for 1 unit we intend one production lot that can be loaded on transportation trucks).

For economic and structural reasons the $s$ and $S$ levels for input inventories are fixed. Structural constraints impose that the orders are fixed to 40 units (due to transportation economies), and the reorder point is fixed to 20 units; hence, the order-up-to level is equal to 60 . In this case, whenever stock level falls down to 20 units an order of 40 units is issued to the upstream supplier; according to these conditions, only the order cycle time is a function of the demand. The fact that $s$ and $S$ levels are fixed reflects the real application situation in which transportation means and production capacity are the main key issues in determining the $s$, and $S$ values. In our case study, the $s$ value is exactly the maximum daily production rate of the plants; this implies that inventories can provide raw materials to plants for 1 day if plants work at maximum capacity level.

Each supply chain actor $k$ computes its own production plan based on estimation of the weekly demand it must face, and its own demand forecast based on the last $p$ orders received by its client according to a moving average forecast technique. The forecast information is used to update, every week $i$, the daily production rate $p r_{i+1}^{k}$.

Let $O_{j, i}^{k}$, for $j=1,2, \ldots, p$, be the last $p$ orders faced by actor $k$ before the end of the week $i$ (equal to the order quantity $Q_{j, i}^{k-1}$ placed by actor $k-1$ to actor $k$ ) at times $t_{j, i}^{k}$, respectively (see Figure 2). For the last downstream actor $k=1$, (i.e., Plant 1 ) we have that $Q_{j, i}^{0}=D_{j, i}$ is the actual customer demand originated at time $t_{j, i}^{1}$.

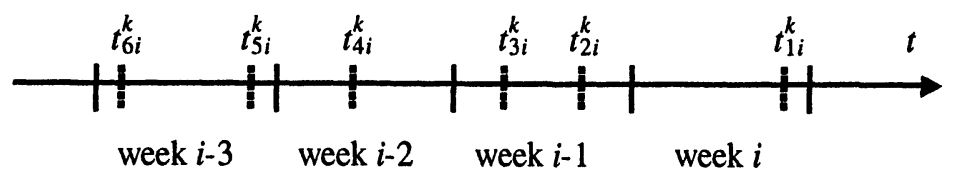

Figure 2. Last 6 orders faced by actor $k$ before the end of week $i$. 
Let $W O_{j, i}^{k}$, for $j=1,2, \ldots, p$, be the same data normalized to the duration of a week (that is, $W O_{j, i}^{k}=W Q_{j, i}^{k-1}=7 O_{j, i}^{k} /\left(t_{j, i}^{k}-t_{j+1, i}^{k}\right)$, with $t_{j+1, i}^{k}$ being the time when the previous $(j+1)$-th order occurs).

The expected weekly order rate $\overline{W O}_{i+1}^{k}$ of actor $k$ for week $i+1$ is $\overline{W O}_{i+1}^{k}=\frac{1}{p} \sum_{j=1}^{p} W O_{j, i}^{k}$.

For the week $i+1$, actor $k$, computes the quantity to produce in the week adding to the expected demand the quantity $2 \sigma_{i+1}^{k}$, in order to assure, for example, a service level equal to $97,72 \%$. Let $\sigma_{i+1}^{k}=\sqrt{\left(p \sum_{j=1}^{p}\left(W O_{j, i}^{k}\right)^{2}-\left(\sum_{j=1}^{p} W O_{j, i}^{k}\right)^{2}\right) /(p(p-1))}$ be the standard deviation of previous $p$ orders arrived. Therefore, we have that the daily production rate $p r_{i+1}^{k}$, in period $i+1$, can be computed as $p r_{i+1}^{k}=\left(\overline{W O}_{i+1}^{k}+2 \sigma_{i+1}^{k}\right) / 7$.

This means that, from one week to another, the input inventory consumption rate and the output inventory replenishment rate change. Due to a lack of information and the distortion caused by the moving average forecast technique, the variation of consumption and replenishment rates do not follow the final customer daily demand rate. This implies an amplification of order variability as one moves up the supply chain, that is the bullwhip effect.

In the next section we describe how the distributed architecture with information exchanging rules helps in reducing the bullwhip effect and the variability of inventory levels in the supply chain, while preserving decisional autonomy for production plans. The solution presented is adequate for MTS (Make to Stock) production systems. For MTO (Make to Order) systems in which forecast is not so important, the scenario could be useful for time to order reduction.

\section{DISTRIBUTED SIMULATION MODEL}

There are many studies and applications regarding distributed simulation. This term can be intended as the use of parallel computing in order to enhance the performance of complex simulation models [1]. In recent works, the term has been used in referring to the simulation of distributed systems. Standard simulation tools, like Arena ${ }^{\circledR}$ (developed by System Modeling Corporation Inc.), have been used to build distributed simulation models to analyze and evaluate virtual (extended) enterprises [11].

In this paper, we built the distributed simulation model by using the Zeus ${ }^{\circledast}$ toolkit, developed by British Telecom [7], to enhance system interoperability, since the toolkit allows the realization of collaborative multi-agent Java applications.

Our application may be seen as a prototype of a tool supporting the decision making process in a virtual (extended) enterprise [10]. 


\subsection{The customer-supplier scenario an the integrated scenario}

In order to analyze information distortion problems illustrated in Section 2.1, we consider two scenarios: 1) a customer-supplier scenario, in which production planning is based on orders placed by a downstream actor and, 2) an integrated scenario, in which macro-modules exchange information on final customer demand, which is used for production management.

The customer-supplier scenario basically represents the original organization of the analyzed extended enterprise. It represents a very common organization scenario for supply chains, in which production is driven by downstream orders. When downstream actor orders arrive, the output inventory management module schedules them following a FIFO (First In First Out) scheduling rule. The orders $O_{j, i}^{k}$, for $j=$ $1, \ldots, \mathrm{p}$, (equal to the order quantities $Q_{j, i}^{k-1}$ that actor $k-1$ send to actor $k$ ), are tracked to forecast the expected weekly order rate $\overline{W O}_{i+1}^{k}$ of actor $k$ for week $i+1$, and the standard deviation $\sigma_{i+1}^{k}$. Hence, the daily production rate of actor $k$ in week $i$ +1 should be $p r_{i+1}^{k}=\left(\overline{W O}_{i+1}^{k}+2 \sigma_{i+1}^{k}\right) / 7$; clearly, this is a target production level, and the actual production rate is affected by both the input inventory level and the output inventory level. Figure 3 explains the orders and forecast information flow.

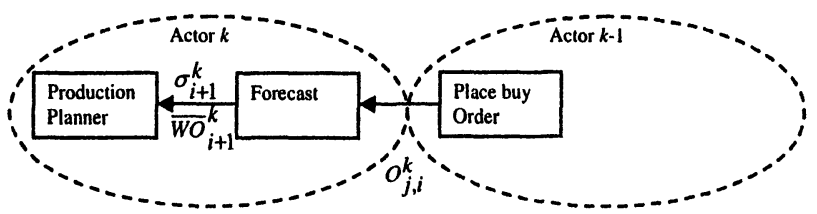

Figure 3. Customer-supplier scenario information flow.

The substantial difference from the scenario with no information sharing and the integrated scenario is given by the different planning policies. In the customersupplier scenario, the production management function relies only on downstream placed orders, while in the integrated scenario the production management module can take advantage of the customer demand information, and precisely, it uses the same demand forecasts of the last downstream actor (Plant 1). Figure 4 shows information flow for this scenario.

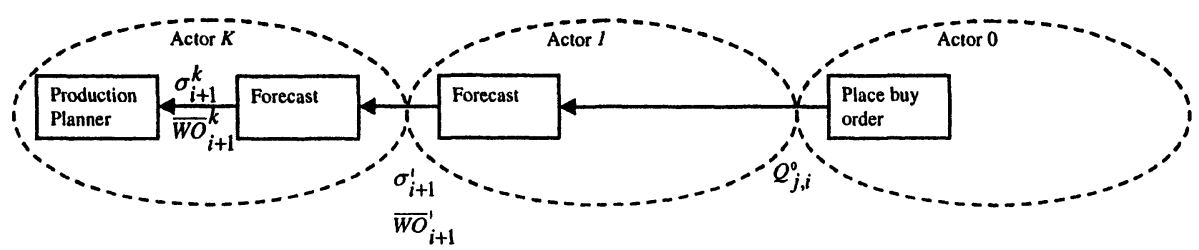

Figure 4. Integrated scenario information flow. 


\section{EXPERIMENTAL RESULTS}

As described before, bullwhip effect has been faced using demand information exchange. We tested our model on realistic data representing a period of one year. The integrated scenario (IS) is compared with the customer-supplier scenario with no information exchange (CS). The final customer demand distribution can be assumed to be a normal distribution with mean value equal to 50 units and standard deviation equal to 4 units.

A supply chain actor computes its own demand forecast based on the last $p=5$ orders received by its client. As for the initial condition for the simulation tests, we assume that input stock levels are set to 20 units for Plants 2, and 3, and 60 units for Plant 1; output stock levels are set to 60 units for Plants 1,2, and 3; daily production rate is fixed to 8 for Plants 1, 2, and 3.

In Table 1, for each scenario, we report the minimum, maximum, and mean values, taken over 5 tests, of $\operatorname{Var}\left(Q^{k}\right)$, and $\operatorname{Var}\left(Q^{k}\right) / \operatorname{Var}(D)$ for Plants 3,2 , and 1 , respectively; these values show the strong reduction of order variability allowed by information exchange. This result is summarized by the reduction of bullwhip effect, quantified as the mean values of $\operatorname{Var}\left(Q^{k}\right) / \operatorname{Var}(D)$ that decreases from 17.12 to 3.59 for Plant 3 and from 5.02 to 3.22 for Plant 2. Clearly, we have the same results for Plant 1 in both scenarios.

Table 1: Simulation scenario results.

\begin{tabular}{|l|ccc|ccc|} 
& \multicolumn{3}{|c|}{ Customer-Supplier Scenario } & \multicolumn{3}{|c|}{ Integrated Scenario } \\
\hline Plant 3 & Min & Max & Mean & Min & Max & Mean \\
\hline $\operatorname{Var}\left(Q^{3}\right)$ & $\mathbf{4 , 1 6}$ & $\mathbf{5 , 7 4}$ & $\mathbf{4 , 9 0}$ & $\mathbf{0 , 9 3}$ & $\mathbf{1 , 0 8}$ & $\mathbf{1 , 0 2}$ \\
$\operatorname{Var}\left(Q^{3}\right) / \operatorname{Var}(D)$ & $\mathbf{1 5 , 3 8}$ & $\mathbf{1 8 , 9 3}$ & $\mathbf{1 7 , 1 7}$ & $\mathbf{3 , 1 8}$ & $\mathbf{3 , 8 7}$ & $\mathbf{3 , 5 9}$ \\
& & & & & & \\
Plant 2 & Min & Max & Mean & Min & Max & Mean \\
\hline $\operatorname{Var}\left(Q^{2}\right)$ & $\mathbf{1 , 2 8}$ & $\mathbf{1 , 5 2}$ & $\mathbf{1 , 4 2}$ & $\mathbf{0 , 8 1}$ & $\mathbf{1 , 0 9}$ & $\mathbf{0 , 9 2}$ \\
$\operatorname{Var}\left(Q^{2}\right) / \operatorname{Var}(D)$ & $\mathbf{4 , 0 8}$ & $\mathbf{5 , 4 1}$ & $\mathbf{5 , 0 2}$ & $\mathbf{2 , 7 9}$ & $\mathbf{3 , 9 7}$ & $\mathbf{3 , 2 2}$ \\
& & & & & & \\
Plant 1 & Min & Max & Mean & Min & Max & Mean \\
\hline $\operatorname{Var}\left(Q^{1}\right)$ & $\mathbf{0 , 2 5}$ & $\mathbf{0 , 3 5}$ & $\mathbf{0 , 2 9}$ & $\mathbf{0 , 2 5}$ & $\mathbf{0 , 3 4}$ & $\mathbf{0 , 2 9}$ \\
\hline
\end{tabular}

Without any information sharing (CS Scenario), the mean value of order variability is augmented by a factor of 4.89 from Plant 1 to Plant 2 and by a factor of 3.45 from Plant 2 to Plant 3.

On the other hand, with information sharing (Integrated Scenario), the variability is augmented by a factor of 3.17 from Plant 1 to Plant 2 and by a factor of 1.11 from Plant 2 to Plant 3.

These results show that improvements at Plant 3 are greater than improvement at Plant 2. Similar results can be deduced from Figure 5 where it is shown improvement in orders fluctuation, faced by Plant 3 . 


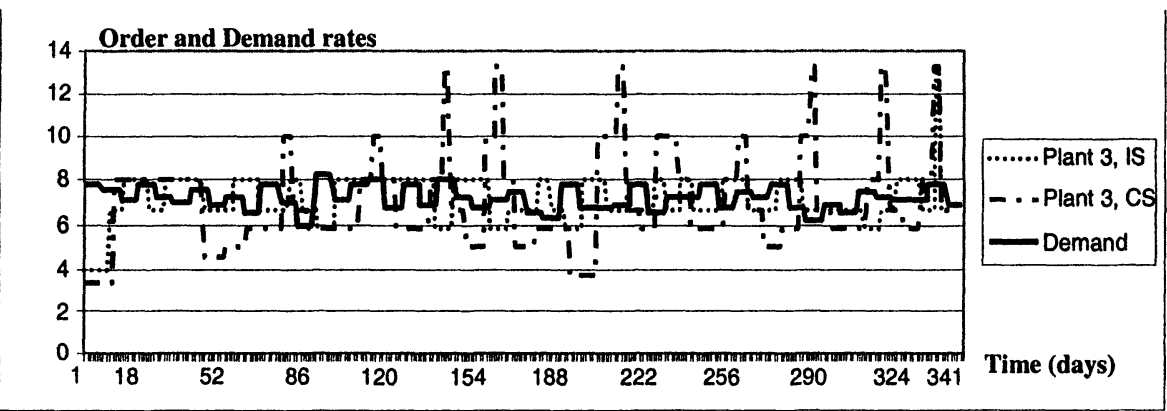

Figure 5: Orders fluctuation improvement for Plant 3.

\section{CONCLUSIONS}

We analysed as demand diffusion influences information distortion in a supply chain of an extended factory. We proposed a distributed simulation model to analyse cooperation between production actors based on coordination. Simulation results on realistic data of an Italian extended factory producing compressors for refrigerators show that information diffusion allows the bullwhip effect phenomenon reduction. We implemented the simulation model on a system architecture by using the Zeus ${ }^{\circledR}$ toolkit. While this solution introduced some degree of complexity in implementing the model, the system architecture allows us to build an infrastructure to support the decision making process in an extended enterprise based on multi-agent systems. Although the simulation results are affected by the real constraints they reflect theoretical results, stating that information sharing help to the reduction of BE.

\section{REFERENCES}

1. Bley H., Wuttke C.C. Distributed Simulation Applied to Production Systems. Annals of the CIRP, 1997 Vol. 46/1, 361-364

2. Boër C.R., Jovane F. Towards a New Model of Sustainable Production: ManuFuturing. The Annals of the CIRP, 1996 vol. 45/1, 415-420.

3. Caplin A. S. The Variability of Aggregate Demand with $(S, s)$ Inventory Policies. Econometrica, 1985 Vol. 53/6, 1395-1410.

4. Chen F., Drezner Z., Ryan J. K., Simchi-Levi D. Quantifying the Bullwhip Effect in a Simple Supply Chain: The Impact of Forecasting, Lead Times, and Information. Management Science, $2000 \mathrm{Vol}$ 46/3, 436-443.

5. Lee H. L., Padmanabhan V., Whang S. Information Distorsion in a Supply Chain: The Bullwhip Effect. Management Science, 1997 Vol 43/4, 546-558.

6. Metters R. Quantifying the bullwhip effect in supply chains. Journal of Operation Management, 1997 N. $15,89-100$.

7. Nwana, H.S., Ndumu, D.T., Lee, L.C. \& Collis, J.C. ZEUS: A Toolkit for building distributed multiagent systems. Applied AI Journal, 1999 Vol. 13 (1), 129 - 185.

8. Shen W., Norrie D.H., Kremer R. Developing Intelligent Manufacturing Systems Using Collaborative Agents. Proceedings of IMS'99, 1999.

9. Simchi-Levi D., Kamisky P., Simchi-Levi E. Designing and Managing the Supply Chain. McGraw Hill, 1999.

10. Swaminhathan J. M., Smith S. F., Sadeh N. M. Modeling Supply Chain Dynamics: A Multiagent Approach. Decision Sciences, 1998 Vol. 29/3, 607-632.

11. Venkateswaran J., Kalachikan Jafferali M.Y., Young-Jun Som. Distributed simulation: ana enabling technology for the evaluation of virtual enterprises. In: B.A. Peters et al. (Eds.). Proceedings of the 2001 Winter Simulation Conference, 2001, 856-862. 